\title{
ARTE CULINARIO Y CREACIÓN POÉTICA EN SOR JUANA INÉS DE LA CRUZ
}

\author{
SOFÍA ORTIZ-Hinojosa \\ Vassar College \\ sortizhinojosa@vassar.edu
}

Sergio Armando Gallegos Ordorica John Jay College of Criminal Justice, CUNY

sgallegos@jjay.cuny.edu

RESUMEN: En el presente artículo, exploramos las conexiones que existen entre el arte culinario y la obra poética de Sor Juana Inés de la Cruz. En particular, usamos un estudio detallado de las analogías que emergen entre la comida y la preparación culinaria por un lado, y la poesía y la composición poética, por otro lado. En este artículo mostramos que el arte culinario funciona como causa o catalizador de la creación poética y que existe una relación íntima y profunda entre el buen sazón, lo bello, y el bien para la monja jerónima.

PALABRAS CLAVE: causa, poesía, comida, buen sazón, bien

SUMMARY: In this paper, we explore the connections between the culinary art and the poetic work by Sor Juana Inés de la Cruz. In particular, following a detailed study of the analogies between, on the one hand, food and culinary preparation, and on the other hand, poetry and composition, we show that culinary art functions as cause and catalyst of Sor Juana's poetic creation. Also, we show that, for the hieronymite nun, there is an intimate and profound relation between good seasoning, beauty and moral good.

KEY WORDS: cause, poetry, food, good seasoning, good

\section{Introducción}

Una de las áreas de la obra de Sor Juana Inés de la Cruz que ha sido hasta ahora poco abordada consiste en la intersección entre la creación poética y el arte culinario. Por un lado, distintas facetas de la creación poética en Sor Juana han sido abordadas por varios estudiosos que se han enfocado en la relación entre sueño, conocimiento y creación poética (e.g., Sabat de Rivers 1976), en cómo la creación poética va de la mano en Sor Juana con una cierta agenda política (e.g., Thomas 2015) y en cómo la creación poética funciona como herramienta pedagógica (e.g., Hansen 2018). Por otro lado, otras distinguidas sorjuanistas (e.g., Lavín y Benítez 2015) han discutido la 
importancia que el arte culinario tiene en Sor Juana dentro del contexto colonial, mostrando cómo el recetario que tradicionalmente se le atribuye a la poetisa (y que incluye muchas recetas de antes, buñuelos y otros dulces: Convento de San Jerónimo 1979/1996) representa una expresión clara y concreta del espíritu barroco novohispano tal como floreció en los conventos femeninos. ${ }^{1}$ Sin embargo, aunque la creación poética y el arte culinario en la obra de Sor Juana han sido tratados por separado con largo detenimiento, no existen trabajos que analicen sus relaciones mutuas, lo que constituye una laguna importante en tanto que ambas actividades se encuentran vinculadas de manera estrecha en varios textos de la Décima Musa. Por ende, el tema del presente ensayo es estudiar la intersección entre creación poética y arte culinario en Sor Juana, con el objetivo de indagar unos principios estéticos y metafísicos de la poetiza. En particular, nos abocaremos a defender tres tesis con respecto a esa intersección: primero, existen analogías sistemáticas entre el arte culinario y la creación poética en la obra de Sor Juana; segundo, la creación poética y el arte culinario son considerados como formas de parto que tienen características innaturales o monstruosas y, tercero, el arte culinario funciona en ciertas circunstancias como motor o causa de la creación poética en Sor Juana. Al defender estas tesis, nuestro objetivo es mostrar que para Sor Juana la creatividad en la cocina nutre y se refleja en la creatividad en la poesía y que existe para ella un relación intima entre el sabor y el bien.

Para sustentar las tesis antes mencionadas, procedemos de la siguiente manera. En la segunda sección, ofrecemos una breve discusión de la naturaleza de la creación poética en Sor Juana, explorando las analogías que hay entre arte culinario y creación poética. En la tercera sección, nos enfocamos en la creación poética y el arte culinario vistos como formas de parto con rasgos monstruosos. En la cuarta sección, argüimos, con base en ciertos poemas, que el arte culinario funciona como motor o catalizador de la creación poética, lo cual no es de extrañar dados los paralelos entre la creación poética y el arte culinario. En la quinta sección, mostramos, apoyándonos en evidencia textual, que existe una relación íntima y profunda entre el

${ }^{1}$ En particular, Lavín y Benítez sostienen lo siguiente: "El dulce nació en la enrarecida atmósfera de la altura espiritual y las pugnas conventuales, entre el deseo y el recogimiento, en un espacio de privaciones y fantasías. Si el dulce mexicano fue femenino por definición, no era atributo exclusivo de la delicadeza sino de un destino carcelario que en la suculencia de alfajores, yemas y suspiros encontraba un puente con el exterior, con ese México del poder político y religioso cuyos favores era menester alcanzar" (2015, p. 19). 
buen sazón, lo bello, y el bien. Finalmente, ofrecemos en la sexta sección una breve conclusión.

\section{Las analogías entre creación poética y arte culinario}

En el villancico VIII (poema 311), Sor Juana equipara la composición del villancico en honor a la Virgen María con la preparación de una ensalada. ${ }^{2}$ En los tiempos barrocos de Sor Juana, la Ensalada era a la vez una forma poética y un estilo musical, que buscaba mezclar "ingredientes" musicales, textuales, y lingüísticos. Así como la preparación de una ensalada lleva varios ingredientes, la creación poética del villancico lleva varios ingredientes o elementos. Con la manipulación imaginativa Sor Juana, la analogía se hace explícita:

\section{Miren que en esos maitines}

Se usa hacer una Ensalada,

Y así, déme cada uno

Algo para aderezarla. ${ }^{3}$

El mismo poema pide que los participantes en la celebración de la Asunción, efectivamente los cantantes del villancico, abastecen los ingredientes para la ensalada comestible que también es Ensalada poética (p. 284). La "frijolera" trae la "lechuga", por ejemplo:

Yo daré las lechugas

Porque son frescas,

Y nadie mejor dice

una friolera

${ }^{2}$ El paralelo y la interdependencia entre la poesía y el arte culinario (o la comida) es un tema tradicional que es abordado por otros poetas anteriores a Sor Juana. En particular, el poeta francés renacentista Pierre de Ronsard en un poema dedicado a su paje Jamyn defiende su decisión de vivir una vida simple, alejada de las intrigas y falsedades de la corte en París, arguyendo que le bastan "su ensalada y su Musa" en los siguientes versos (1866, p. 88): “Tu me diras que la fièvre m'abuse; Que je suis fol, ma Salade et ma Muse [...]" [Me dirás que la fiebre me abusa; Que yo estoy loco, mi Ensalada y mi Musa [... ]; la traducción es nuestra.]

${ }^{3}$ Sor Juana Inés de la Cruz 2010, p. 284. Como los poemas se toman de la obra mencionada, en adelante sólo se citarán los números de página. 
Otros llevan el aceite y la sal, de "aderezo". Al componerse los ingredientes de la ensalada se tornan intercambiables con los ingredientes del villancico (p. 285). Por ejemplo, las lechugas son intercambiables con un enigma:

Pues en lugar de lechugas,

Yo un engima propondré

$\mathrm{Y}$ el aceite comestible, que se usa de aderezo, es intercambiable con el Aceite sacramental que se usa en ritos cristianos, que a la vez es simbolizado por la Virgen (p. 285):

Yo, del aceite en lugar,

diré que la singular

Virgen como Aceite fue.

Finalmente, la sal de la ensalada funge como metáfora para virtud virginal (p. 285):

Yo diré que fue la Sal

Su Pureza sin igual:

Pues por tener tal blasón

Ignoró la corrupción

que general pena fue

Así vemos que para la poetisa los ingredientes comestibles, poéticos, y sagrados son enteramente intercambiables. El pueblo, quien proporciona los ingredientes concretos, asimismo se asemeja a la poetisa, quien compone el villancico. De manera dinámica los cantantes se involucran en esta composición. A la vez la poetisa intenta reflejar con sus imágenes poéticas los ingredientes de la Santidad de la Virgen, los cuales son igualmente elementos esenciales de la creación mundial y de la asunción espiritual. Efectivamente, en este poema la creación es tanto un acto concreto y colectivo de arte culinario, un acto abstracto de arte poético, y un acto trascendente y de elevación espiritual. A este respecto, Sor Juana hace eco implícitamente de la palabras de Diotima que Sócrates refiere en el Simposio (205b-c): "Ya sabés que la palabra 'poesía' tiene numerosas acepciones y expresa 
en general la causa que hace que una cosa, sea la que quiera, pase del no-ser al ser de suerte que todas las obras de todas las artes son poesía, y que todos artistas y todos los obreros son poetas."

Se puede percibir algo similar en el villancico V (poema 221) (p. 208), en el cual el panal, la leche y la miel son referentes a las palabras de la Virgen María, el texto de la Biblia:

la de hablar dulce,

cuyos labios bellos

destilan panales,

leche y miel vertiendo.

La belleza de la voz de María, como voz poética, es voz de santidad Bíblica. Sin embargo, esto se entiende a través de la metáfora de miel y de leche, del sabor dulce, el cual se produce en los labios y las palabras de la Virgen. El arte culinario se utiliza para comunicar efectivamente el arte espiritual, pero este se accede a través de la forma poética. Las palabras santas tienen el efecto de crear los dulces naturales, como el panal y la miel del abejón, así como la leche del ganado.

La idea de la creación, de la elaboración de productos materiales a través de procesos activos, alquímicos, y espirituales, es central en la obra de Sor Juana en su totalidad. Como veremos en la cuarta sección, los principios metafísicos de causalidad que forman la base del pensamiento de la monja jerónima se influyen en la filosofía clásica y la escolástica, por ejemplo, en el emparejamiento y el alternar de la potencialidad y de la actualidad de las propiedades. Pero a Sor Juana se puede sumar también la influencia hermética, según la cual la investigación del mundo creado era a su vez una investigación espiritual. Comenta Elías Trabulse (1982, p. 83), "para Sor Juana, como para estos hombres de ciencia el papel 'científico' era el de sintonizas con el mensaje del universo, o sea del cosmos, cuajado de maravillas por obra de ese gran mago que era Dios, verdadero arquitecto del mundo". Por ejemplo, en la Loa para el Auto del Divino Narciso, Sor Juana equipara al Dios católico con el Dios de las semillas. Si tomamos seriamente la visión hermética de que el mundo entero es un producto de la magia de la creación, y de que todos sus procesos son procesos alquímicos o mágicos, tanto la investigación científica como las actividades creativas resultan ser actos en sí mágicos: son 
actos de creación análogos, si es que menores, al acto de la Creación del mundo. ${ }^{4}$

Para Sor Juana en particular, la creación parece ser un acto de composición, de una reunión de elementos que en conjunto forman un entero. Ya vimos en los dos villancicos ya comentados ejemplos de esta visión. Sin embargo, el acto de reunión puede en veces transformar a los elementos para generar una totalidad nueva y distinta a sus partes. Comenta la monja jerónima en su Respuesta a Sor Filotea,

Pues ¿qué os pudiera contar, señora, de los secretos naturales que he descubierto estando guisando? Ver que un huevo se une y fríe en la manteca o el aceite y, por el contrario, se despedaza en el almíbar; ver que para que el azúcar se conserve fluida basta echarle una muy mínima parte de agua en que haya estado membrillo u otra fruta agria; ver que la yema y clara de un mismo huevo son tan contrarias que, en los unos, que sirven para el azúcar, sirve cada una de por sí y junto no. (2010, p. 838)

El descubrimiento del poder alquímico en la cocina es el catalizador de su entendimiento del acto creativo: es un poder que altera a sus elementos a la vez que los compone. Este concepto une, finalmente, a los distintos actos creativos, como el de escribir, y el de cocinar.

Podemos ver otro acto de composición poética-culinaria en el increíble poema Agrísima Gila (poema 72) (p. 92), en el cual las partes corporales mismas de la destinataria "Gila" se comparan con sabores agrios y ácidos. Aquí compartimos el texto en su totalidad:

Agrísima Gila, $\quad$ Por San Juan de Lima

Que en lugar de dar Te quiero pintar,

Confites al gusto, Porque entre tus agrios

Dentera le das: tengas éste más.

El ámbar y mirra se quedó en agraz.

En tu pelo está

Derretido: mira $\quad$ El carmín más vivo

Si amargo será. $\quad$ En tu boca está,

\footnotetext{
${ }^{4}$ Es por ello que tanto la creación poética como el arte culinario se encuentran vinculados a la idea de parto (y, en particular, de parto monstruoso) como mostramos en la tercera sección.
} 
A la vista hermoso

Tu frente el jazmín Y amargo al gustar.

Pretende afeitar,

Pero al fin se sale Tu cándido cuello

Con ello el azahar. Tan nevado está,

Que sobre el limón

La tinta a tus cejas Le puso la sal.

El color les da,

Con que a alcaparrosa De cuajada leche

Y agallas sabrán. Tus manos serán,

De la que al sereno

Son aceitunados Se pasó a acedar.

Tus ojos, y están

Bien aderezados $\quad \mathrm{Al}$ coturno de oro

De orégano y sal. Los ojos se van,

Mas se experimentan

Quiso a tus mejillas Píldora al tragar.

Teñir un lagar;

Mas, como eres niña, $\quad \mathrm{Si}$ este tu retrato

Muy agrio no está, De tu natural.

Ponle tú la hiel

En este poema Sor Juana ilustra, a través de la metáfora de pintura y de ingredientes culinarios como las frutas cítricas (los agrios, el limón, la lima) y sus flores (el azahar), las aceitunas, las alcaparras, la leche cuajada, el vino, el orégano, y la sal, los aspectos agrios de Gila, quien evidentemente es una amargada. La poética caracterización se completa a través de una creación culinaria de sabores amargos, ácidos, y salados. Se contrastan a su vez con potenciales sabores dulces o suaves que pudieran haberse producido por procesos similares: en vez de dar confites, adornarse con jazmín, producir vino, o hacerse 
queso fresco, Gila da "dentera", luce flores de naranjo, produce agraz, y se convierte en crema agria.

Igualmente, la forma poética transforma a su sujeto, que ordinariamente sería alabado, en una versión disminuida o alterada. El poema es una endecha, la cual típicamente se usaba para lamentar la muerte de un ser querido o para elogiar un personaje difunto. Aquí probablemente Sor Juana utiliza la endecha de manera irónica, con versos de arte menor en seis sílabas que a veces alternan con versos de cinco sílabas, en sí una disminución de su forma más común, que es heptasilábica. Esta modificación poética es quizás análoga a los procesos de amargar culinariamente el parecer de Gila. Aún el mismo acto de escribir compone y a la vez sazona el rostro de Gila: el color de las cejas viene de la tinta, sin embargo, le presta un sabor que, en vez de ser bello y dulce como la tez de una doncella, es tanto amargo como asqueroso (las "agallas", palabra que tiene significado abstracto de "atrevimiento", son excrecencias de árbol producidas por picaduras, cuyos contenidos tenían a veces uso medicinal).

Asimismo, en otro proceso transformativo, el difunto de este poema no es un ser humano sino el buen humor o quizás la amabilidad de la destinataria Gila. En vez de elogiarse a través de la creación poética, a Gila se le desprecia o se hace burla de ella por ser desagradable. Este desagrado tiene forma gustativa, de acidez y de amargura. Así, la creación poética comparte aspectos de la creación culinaria: ambos se manufacturan o se componen a través de la combinación y alteración de sus partes integrantes. El proceso de composición poética y culinaria es el proceso de reunir y modificar a distintos elementos que, en su conjunto, forman una compleja unidad que se experimenta de manera estética.

En el poema 51 (p. 73) Sor Juana hace aún más explícita la conexión entre la creación poética y la creación culinaria, en cuanto cuestiona por qué sus poemas se han celebrado de sobremanera:

¿Qué mágicas infusiones

de los Indios herbolarios

de mi Patria, entre mis letras

el hechizo derramaron?

Aquí las "letras" de la poesía son potenciales recipientes de una infusión herbolaria: es decir, las palabras en sí se vuelven objeto culinario, capaz de mezclarse con los ingredientes de la infusión, 
y por ende, de crear el hechizo que se manifiesta a través de tal preparación. El poder de la palabra se asemeja a un poder mágico, el de la composición casi alquímica. Se escuchan en estos versos ecos del hermetismo que tanto le fascinaba a Sor Juana. En este caso, la poetisa se muestra escéptica del poder intrínseco de sus versos, por lo cual postula que quizás una magia ajena a su persona y con carácter de poción es la causa del atractivo de su poesía a las "plumas de Europa" quienes son sus admiradores. Esta bebida encantada, una creación culinaria, es la que sustituye al encanto de la palabra, de la creación poética. Ambas creaciones parecen intercambiables en su obra.

Otro momento en el cual podemos ver realizada la analogía de la poesía con la cocina es en el romance 44 (p. 59) que Sor Juana escribe para acompañar el regalo de "un recado de Chocolate" para la Condesa de Galve, así juntando el acto de escribir con el acto de confeccionar:

[...] como es día de licor,

Éste, aunque no muy bendito,

pues en señal de su origen

lleva el pulvis es escrito, os envía cierto afecto $[\ldots]$

Hasta el recado tasado

va, tan mudo y sin rüido,

que va guardando secreto

las ruedas del molinillo.

Sor Juana nota que el recado va "mudo", es decir, que se comunica no en voz alta, sino a través del regalo del chocolate, que esconde o contiene su mensaje de afecto a la Condesa. Asimismo, el romance que adjunta la poetisa comunica el mismo mensaje, igualmente "mudo". Entre comentaristas tanto Artemio de Valle-Arizpe como Mónica Lavin y Ana Benítez nos dan razones para pensar que Sor Juana era conocida por sus habilidades culinarias y, en particular, por sus confecciones dulces. Por lo tanto, podemos pensar que el chocolate lo pudo haber molido y confeccionado la misma Sor Juana. Va "tasado", es decir, medido, tanto por su valor (a pesar de 
"ser polvo") como por su tamaño. El poema también es algo que va "tasado" o medido, de acuerdo con su versificación en sílabas.

Las palabras "pulvis es" en el poema hacen referencia tanto al polvo de chocolate que se usa para hacer chocolate líquido (el "licor" que es "no muy bendito"), como a las palabras de Dios en Génesis al expulsar a Adán del Paraíso: "Recuerda, hombre, que polvo eres, y al polvo volverás." Esta alusión poética sirve a la vez de broma y de comentario irónico, ya que el chocolate era una sustancia tanto cara como popular en el siglo XVII. El convento de las monjas jerónimas era de los pocos sitios donde se podía trabajar el chocolate con regularidad, y en algunas partes las monjas se dedicaban a su producción. Por ende, el "recado" de chocolate es tan humilde (por ser pequeño) como el "polvo" del que venimos, sin embargo, es un regalo apropiado hasta para virreinas como la Condesa de Galve. Se podría especular que el Romance que la poetisa compuso tendría comparable valor, ya que pocas mujeres de la época tendrían la capacidad de leer y escribir, y mucho menos de componer poesía.

Consideremos también otro poema que usa Sor Juana para darle atenciones a la Condesa de Galve, el Romance 43 (pp. 57-58):

[...] He pasado pensativa

Sobre un libro y un bufete

(porque vayan otros sobres)

Sobre el amor que me debes [...]

En Ovidio, como es

Poeta de las Mujeres,

hallé que al fin los pintares

eran como los quereres;

Y hallé a escoger, como en peras

Unas bellezas de a veinte

A lo de ¿qué quereís, pluma?

Que están diciendo comedme, en los prados, más que flores, en el campo, más que nieves, 
en las plantas, más que frutos,

y en las aguas, más que peces.

[...] y en fin, la Casa del Mundo,

que tantas pinturas tiene

de bellezas vividoras,

que están sin envejecerse,

cuya dura cama, el Tiempo

Que todas las cosas muerde

Con los bocados de siglos

No les puede entrar el diente [...]

Aquí Sor Juana se describe escogiendo palabras como cuando uno escoge peras, según las que apetecen o que inspiran el antojo. En el caso de las palabras que escribirá la pluma, lo que se busca es belleza descriptiva; en el caso de las peras, se busca el placer gustativo. Tanto las palabras del libro como las comidas del bufete sobre las cuales se "pasa pensativa" la poetisa son catalizadoras para la creación de la obra poética. Abundaremos más sobre este tema en la cuarta sección. Sor Juana escoge palabras y temas para su poesía "como en peras" que en su belleza apetecen como para comerse, o, en este caso, para escribirse: y encuentra, enseguida en el poema, varios ejemplos tentadores de grandes y bellas mujeres en diversos poetas clásicos, hasta que finalmente se rinde, por no poder encontrar belleza semejante a la de la Condesa ni en estas poesías tan magistrales.

La metáfora entre el alimento y la escritura se extiende hacia la conclusión, en donde el Tiempo se describe como comiendo o mordiendo "todas las cosas". Sin embargo, el Tiempo no puede comerse o acabar con las bellezas de los poetas "que están sin envejecerse". Es decir, aunque las bellezas que Ovidio, Homero, Virgilio, y los demás poetas describen son las más deseables, las delicias que más inspiran el antojo poético, aún el mismo Tiempo no logra consumirlas, ya que lucen tan eternas e inviolables. La poesía es así un destello que pareciera consumible, pero que en su perfeccionamiento se muestra resistente al desgaste o a la fugacidad de los alimentos mundanos. En 
esta comparación el arte culinario hace resonancias con el arte poético: ambos realizan productos, como los frutos del campo o los peces de las aguas, cuyo potencial apunta a la eternidad, y los cuales son "cosas" que el Tiempo se puede tragar. Quizás en esta comparación vemos la limitación gastronómica, ya que el alimento que se consume a su vez deja de existir, mientras que el poema, al consumirse, alarga su perduración. Recordando ahora la noción de creación o poiesis, se nota en este poema una divergencia potencialmente importante en la metafísica de estos distintos objetos. ¿Habrán, quizás, diferencias entre las potencialidades de distintas creaciones, basadas en su causa material o en su causa eficiente?

Para cerrar esta sección, debemos discutir un ejemplo final de la relación entre la creación culinaria y la creación poética en la obra de Sor Juana. Este se encuentra en el poema 274 (p. 253), donde de nuevo utiliza la compositora la metáfora de la Ensalada:

Y haremos una Ensalada

De algunos picados versos,

Más salada que una hueva

Y más fresca que el invierno

Los versos de la Ensalada poética son "picados" como los ingredientes de la ensalada comestible, y la poesía es "salada" y "fresca" al igual que el platillo. De hecho, en esta obra la Ensalada poética hasta se confunde con la ensalada comestible, ya que se describe una parte de ella como "bocado" (p. 253):

Bueno está el Latín; mas yo

De la Ensalada, os prometo

Que lo que es deste bocado

Lo que soy yo, ayuno quedo.

El "bocado" al cual se refiere es una sección del poema que está en Latín, que a pesar de haberse consumido, deja al interlocutor en "ayunas", por ser difícil de entender. Como remedio, la poetisa compone unas secciones adicionales en vernáculo popular, como para "nutrir" mejor al público. Ofrece enseguida el cantante de la próxima sección una cuajada, que es un postre popular derivado de la leche; 
e importantemente se le ofrece a la Virgen María, cuya asunción se debe estar celebrando, para pedirle que preste su presencia mundana un rato más (p. 253):

¿Qué cuaja, qué cuaja, qué cuaja, qué cuaja te doy.

- Espela, aún no suba,

que tu negro Antón

te guarra cuajala

branca como Sol.

A este platillo le siguen ofrendas de garbanzos tostados y salados, y también ofrendas de camote y de requesón. En efecto, esta Ensalada se compone de diversos componentes que se pueden "saborear" oralmente: unos por ser hablados, otros por ser probados (p. 253).

- Garvanza salara

tostada ri doy,

que compló Cristina

Máse de un tostón.

$[\ldots]$

- Camotita linda,

fresca requesón,

que a tus manos beya

parece el coló.

La misma alabanza poética en este poema consiste en la descripción de los alimentos presentados en el altar. El requesón se parece al color bello de las manos virginales. A la vez, a la Virgen se le dice "Camotita linda", una expresión de cariño que la compara con el rico vegetal. La ofrenda de los versos poéticos se asemeja a la ofrenda de los alimentos en el altar, los cuales se consumen en un acto de íntima comunión con lo divino. De hecho, en el poema 343, Sor Juana describe a los personajes y eventos bíblicos como proveedores de alimentos que se sirven en "la Mesa Celestial", que se consumen al leer los versos bíblicos, y en el poema 344, se pregunta cómo los 
fieles deben venir a "la Mesa del Altar" (p. 307). Así, vemos que Sor Juana equipara el acto de composición poética, del canto de los devotos participantes de ritos eclesiásticos que sirve de adoración divina, con la creación y degustación culinaria, que podría, a la manera de antiguos ritos antecedentes a la conquista, hasta inspirar las atenciones divinas. La producción y el consumo tanto de poesía como de alimentos sirven de hermanados actos de devoción espiritual y de comunión con lo divino. En la poesía de Sor Juana el vínculo entre los productos de la creatividad humana y el poder de creación divino es estrecho.

\section{La creación poética como parto monstruoso}

Para Sor Juana, la creación poética se presenta en varios lugares de su obra como una forma de parto. En este sentido, Sor Juana hace eco de una larga tradición cuyos distinguidos antecedentes cuentan con filósofos como Platón (Simposio) y Aristóteles (Poética), así como poetas como Ovidio, Lope de Vega y William Shakespeare, entre otros. Sin embargo, a diferencia de sus predecesores, Sor Juana enfatiza que la creación poética es, en su caso, un tipo de parto cuyas características son innaturales o monstruosas.

En particular, en el caso de varios poemas, Sor Juana menciona que la creación poética es similar a un parto monstruoso en el sentido que involucra varios rasgos que causan asombro en tanto que son innaturales. Por ejemplo, en el poema 48 (p. 62) en el cual Sor Juana responde a un caballero peruano que le aconsejó hacerse hombre para poder llevar mejor a cabo sus ambiciones poéticas, Sor Juana responde de manera profundamente sutil. Primero, recuerda a su lector el papel tradicional de las Musas como madres de la poesía:

Señor, para responderos

Todas las Musas se eximen

Sin que haya, ni aun de lismona,

Una que ahora me dicte

Y siendo las nueve Hermanas

madres del donaire y del chiste 
No hay, oyendo vuestros versos,

Una que chiste ni miste.

Tras haber enfatizado en estas dos estrofas iniciales la creación poética como una forma de parto que es llevado a cabo por mujeres, Sor Juana se enfoca en otra parte del poema en resaltar la absurdidad de la sugerencia del caballero peruano por medio de una profunda ironía: promete seguir en la medida de lo posible el consejo del caballero para llevar a cabo su ambición literaria, pero también resalta que en cierta medida ya lo ha seguido puesto que, tras haber ingresado al convento, no puede ser ya mujer puesto que le es imposible ejercer las tareas y funciones que tradicionalmente son consideradas como esenciales para una mujer (en particular, las tareas domésticas y las funciones reproductivas):

$\mathrm{Y}$ en el consejo que dais,

Yo os prometo recibirle

$\mathrm{Y}$ hacerme fuera, aunque juzgo

Que no hay fuerzas que entarquinen

Porque acá Sálmacis falta

En cuyos cristales dicen

Que hay no sé que virtud de

Alientos varoniles

Yo no entiendo de esas cosas

Sólo sé que aquí me vine,

Y sólo sé que mi cuerpo

Sin que a uno u otro se incline,
Porque, si es que soy mujer,

Ninguno lo verifique

Y también sé que en latín

Sólo a las casadas dicen

Uxor, o mujer, y que

Es común de dos lo Virgen

Con que a mi no es bien mirado

Que como a mujer me miren

Pues no soy mujer que a alguno

De mujer pueda servirle;

Es neutro, o abstracto, cuanto

Sólo el alma deposite

Por ello, Sor Juana caracteriza a la actividad poética como un parto con rasgos innaturales o monstruosos: le es imposible realizarlo como mujer, por lo que se le pide que para llevarlo a cabo se convierta 
en hombre (lo cual es innatural o monstruoso). ${ }^{5} \mathrm{Y}$, como esto es físicamente imposible, Sor Juana enfatiza que, al haber escogido una vida religiosa en el convento, esto la ha tornado en un ente neutro o asexuado que, paradójicamente, se encuentra en una mejor postura para llevar a cabo su ambición de creación poética.

Sor Juana no sólo considera la creación poética a través de metáforas de parto, sino también a través de metáforas de preparación culinaria que se encuentran asociadas al parto. En otro poema (poema 50) (p. 71) donde Sor Juana responde a otro caballero peruano que le había alabado llamándola "Mexicana Musa", Sor Juana manifiesta de forma clara que la creación poética es un forma de parto al hacer énfasis en que, al leer a Ovidio, Homero y Virgilio (acto que equipara con beber un vino embriagante), el hecho de consumir fragmentos de las obras de los poetas antes mencionados (fragmentos que compara con los polvos usados para una infusión) tiene como consecuencia el desarrollo de su capacidad de versificar:

Pero esto no pasó de

Consultar acá conmigo,

Si podré entrar por fregona

De las Madamas del Pindo

Y si beber merecía

De los cristales nativos

Castalios, que con ser agua

Tienen efectos de vino

Pues luego al punto levantan

Unos flatos tan nocivos
Se han mostrado en los escritos.

Entre cuyos jarros, yo

Busqué por modo de vicio

si les sobraba algún trago

Del alegre bebedizo

Y (si no me engaño) hallé

En el asiento de un vidrio

De una mal hecha infusión

Los polvos más desleídos.

${ }^{5}$ Para ser precisos, Sor Juana se ve atrapada, según nosotros, en un dilema en el que cualquier alternativa la lleva a ser concebida como un ser monstruoso o innatural. En efecto, por un lado, si intenta seguir el consejo del caballero peruano, eso la lleva a cruzar la frontera de género y convertirse en un fenómeno o en un ser monstruoso. Por otro lado, si decide conservarse como mujer, eso también la acula a ser considerada como un ser monstruoso, puesto que, como Kirk (2009, p. 423) ha enfatizado, "en los tratados biológicos se consideraba que la fuerza de la imaginación femenina era capaz de provocar un parto monstruoso". 
Que dando al seso vaivenes

Hacen columpiar el juicio, No sé sobras de quién fueron Pero, según imagino,

De donde se ocasionaron Fueron de un bribón aguado

Los traspieses que dio Ovidio, Pues hace efectos tan fríos Los tropezones de Homero,

Los vaguidos de Virgilio

Versifico desde entonces

Y de todos los demás

$\mathrm{Y}$ desde entonces poetizo,

Que fúnebres o festivos ya en Demócritas risadas,

Conforme les tomó el Númen ya en Heráclitos gemidos.

Como podemos apreciar, la creación poética tiene un doble aspecto o naturaleza para Sor Juana: es a la vez concebida como un tipo de parto intelectual monstruoso (en tanto que el vino o licor embriagante de las Musas genera unos gases o flatos que desbalancean el equilibrio de la razón y turban el juicio) y como un tipo de preparación culinaria (que involucra varios polvos o ingredientes que son mezclados para crear una infusión). En este sentido, dado el paralelo entre la creación poética y el arte culinario, no es extraño que el arte culinario funcione en la obra de Sor Juana como catalizador o causa de la creación poética puesto que ambos van frecuentemente de la mano. Resulta, entonces, que para Sor Juana las sustancias de la poesía y la comida parecen similares tanto en su composición o materialidad como en su capacidad causativa.

\section{El arte culinario como causa o catalizador de la creación poética}

Para Sor Juana, el arte culinario no sólo es equiparado con la creación poética en varias ocasiones, sino podemos mostrar que el arte culinario funge como catalizador o causa de la creación poética. En particular, de acuerdo con nuestra interpretación de Sor Juana, el arte culinario funciona en varias dimensiones análogas a las cuatro causas de Aristóteles. Para empezar, el arte culinario opera en ciertas ocasiones como un molde o una forma que hace posible la creación poética. En otras circunstancias, funciona como parte de los materiales o ingredientes de la creación poética. En tercer lugar, el arte culinario funge en ciertos poemas como motor o estímulo que hace posible la creación poética para Sor Juana y, finalmente, en algunos 
contextos el arte culinario funge como objetivo o fin de la creación poética.

Numerosos comentadores de Sor Juana como Mauricio Beuchot y Alejandro Soriano Vallès (2000) han enfatizado en sus estudios la profunda influencia del pensamiento aristotélico (en especial, en su vertiente escolástica desarrollada por Tomás de Aquino) en la obra de Sor Juana. Ahora bien, dado el papel central que ocupan en la metafísica de Aristóteles las diversas causas así como en la extensa y detallada discusión que el Aquinate hace de ellas en su obra (en especial, en el Comentario a la Metafísica), no es sorprendente encontrar múltiples referencias en Sor Juana a la importancia y los distintos papeles que tienen las diversas causas en el orden del mundo. En particular, en el poema 56 (p. 76), Sor Juana enfatiza la importancia del término o la causa final del amor (que es Dios entendido como el Bien Supremo) y la distingue de la causa formal (que un cuidado o deseo del amante), de la causa eficiente (que es el amante que trae consigo el cuidado o deseo) y de la causa material (que es una sensación de dolor o tormento causada por la ausencia del objeto amado):

Traigo conmigo un cuidado,

y tan esquivo, que creo

que aunque sé sentirlo tanto

aun yo misma no lo siento

Es amor; pero es amor

Que, faltándole lo ciego,

Los ojos que tiene son

Para darle más tormento.

El término no es a quo,

que causa el pesar que veo:

que siendo el término el Bien

todo el dolor es el medio 
Así como distingue Sor Juana en estas estrofas las distintas causas del amor de acuerdo con la taxonomía aristotélico-tomista, también ofrece varias caracterizaciones en múltiples lugares de las distintas causas de la creación poética. Por ejemplo, en algunos poemas, el arte culinario opera como molde o forma de la creación poética. Como ya hemos mencionado en la segunda sección al discutir el poema 311, Sor Juana establece una analogía entre la ensalada, que es originalmente un plato frío compuesto por una mezcla de hortalizas cortadas y aderezadas (en particular, con sal), y el villancico, que es una forma poética y musical de estructura polifónica y compuesta en lengua vernácula que originalmente versaba sobre temas profanos (aunque fue paulatinamente orientada a temas religiosos como instrumento evangelizador).

Ahora bien, para nosotros la analogía entre la ensalada y el villancico no se limita en este caso a resaltar meramente los paralelos entre el plato y el poema, sino en mostrar que la forma misma del plato se manifiesta en la forma de la creación poética. Esto se debe a que la forma del plato consiste en una mezcla de varios ingredientes, con sabores y texturas específicas, que dan pie por medio de su combinación a una sazón y una consistencia particulares del producto final. Para Sor Juana, la forma de la ensalada da pie a la forma del villancico en el sentido de que cada voz que participa en el villancico contribuye, por su textura y timbre específicos, a una composición musical y poética balanceada y armónica. Podemos apreciar claramente esto en las siguientes estrofas donde las voces que cantan el villancico son explícitamente caracterizadas por Sor Juana como los ingredientes cuya mezcla específica genera una ensalada (p. 285):

El aceite a mi juzgo

que me compete,

Que es mi voz clara y blanda

como el aceite.

Lo negaran los niños,

Que aceite atizan

Porque traen de ordinario

Sus lamparillas. 
Yo, por mi mucha gracia,

Dar sal me place

Porque con mi voz tengo

Quinientas sales.

No esté tan engreído

Con ese tiple

que la sal Mejicana

Es tequesquite.

Como podemos ver, para Sor Juana el arte culinario opera claramente en este fragmento como causa formal de la creación poética, puesto que la forma del villancico deriva de la forma de la ensalada. Pero no sólo se limita el arte culinario a ser causa formal de la creación poética. En otras circunstancias, el arte culinario funciona también como causa material de la creación poética, pues los elementos mismos del plato o de la preparación culinaria son partes del poema. Por ejemplo, en el poema 72 (Agrísima Gila) que hemos mencionado en la segunda sección, Sor Juana describe distintas partes del cuerpo de la destinataria del poema como si fueran ingredientes de un plato:

La tinta a tus cejas

El color les da,

Con que a alcaparrosa

Y agallas sabrán.

Son aceitunados

tus ojos, y están

bien aderezados

de orégano y sal. 
De forma paralela, el arte culinario opera para Sor Juana como causa material de la creación poética en tanto que ambos se compenetran y complementan mutuamente en ciertas ocasiones por el hecho que ambos constituyen la misma materia de un cierto objeto. Por ejemplo, el poema 31 (pp. 4l-42) es parte de un regalo que Sor Juana le hizo a la virreina María Luisa Manrique de Lara con motivo de la celebración de Pascua, y esta parte del regalo describe la otra parte que consiste en unos peces y unas gallinas explícitamente preparados para la cena pascual:

Allá van para que pases

gustosas Pascuas, Señora,

Con aquesos bobos versos,

Aquesas gallinas coplas.

Como quien soy te regalo,

como quien eres perdona,

y ambas habremos cumplido

Con todo lo que nos toca.

Tú eres Reina y yo tu hechura;

tú Deidad, yo quien te adora;

tú eres dueño, yo tu esclava;

Tú eres mi luz, yo tu sombra.

Para nosotros, la primera estrofa es una muestra clara de que el arte culinario funge aquí como causa material de la creación poética, ya que Sor Juana toma los sustantivos que designan de forma primaria a los animales y por metonimia a los platos ("bobo" y "gallina") y los utiliza como adjetivos en el poema para describir el poema mismo: a los versos se les califica como bobos (o simples), mientras que a las coplas se les califica como gallinas (o sumisas). Estos calificativos sirven muy claramente para introducir la posición de Sor Juana con respecto a la virreina, quien es su protectora y mecenas, y a quien se le describe con detalle en la tercera estrofa. 
Además del papel del arte culinario como causa material de la creación poética, otra dimensión del arte culinario que aparece en la obra de Sor Juana es su función como motor o estímulo de la creación poética - es decir, como causa eficiente-. En efecto, en algunos poemas como en el poema 352 (p. 311), la cena eucarística se concibe como motor o estímulo no sólo de la creación poética, sino de la creación de María y de la salvación del hombre:

Queriendo hacer un convite

la eterna Sabiduría

para preparar la mesa

antes la casa edifica:

Que a tal Comida,

ha de ser Casa Nueva,

La que le sirva.

Casa Virgen, Casa Intacta

sólo puede ser María

de sólo Dios habitada

y para Dios erigida:

que sin mancilla,

Para ser templo suyo

fue concebida.

El papel del arte culinario como estímulo o motor de la creación poética también surge en otras obras como en el poema 274 (p. 253), que es un villancico en el cual Sor Juana yuxtapone dos cánticos a la virgen María en una composición que mezcla la liturgia oficial de la Iglesia católica (que requería el uso del latín) con el uso de las lenguas vernáculas habladas por distintos grupos de la Nueva España. En particular, después del cántico en latín, Sor Juana introduce deliberadamente en el villancico una sección en la que, en tono jocoso, reconoce que la mayor parte de los fieles quienes escuchaban el villancico en la catedral no comprendieron el cántico y les ofrece algo que pueden entender: 
3. Bueno está el latín, mas yo

De la Ensalada, os prometo que lo que es de este bocado

Lo que yo soy, ayuno quedo

Y para darme un hartazgo, como un Negro camotero quiero cantar, que al fin es cosa que gusto y entiendo;

Pero que han de ayudar todos. Tropa. -Todos os lo prometemos 3. -Pues a la mano de Dios, Y transfórmome en guineo

\section{Negro}

¿Qué cuaja, qué cuaja, qué cuaja, qué cuaja te doy.

- Espela, aún no suba,

que tu negro Antón

te guarra cuajala

branca como Sol.

- ¡Rorro, rorro, ro!

- Garvanza salara

tostada ri doy,

que compló Cristina

Máse de un tostón. 
— Rorro, rorro, ro!

- Camotita linda,

fresca requesón,

que a tus manos beya

parece el coló.

- Mas que ya te va,

ruégale a mi Dios

que nos saque lible

de aquesta plisión.

- ¡Rorro, rorro, ro!

En este fragmento del villancico podemos apreciar que el villancico mismo en su totalidad se concibe como alimento. Dado que la parte en latín no la comprende la mayoría de la audiencia (y algunos de los cantantes), muchos fieles se quedan figurativamente en ayunas. Para que puedan comprender (o darse un hartazgo), Sor Juana hace que los intérpretes canten una parte del villancico en lengua vernácula y los hace adoptar a propósito la dicción de los esclavos negros, que constituían el estrato más bajo de la sociedad novohispana, con la intención probable de mostrar que en principio todos, en tanto que cristianos, pueden participar plenamente en la celebración. Según nosotros, esto constituye un ejemplo claro de cómo el arte culinario funciona como causa eficiente de la creación poética, pues son tanto el hambre de entendimiento como la sed de participación en la celebración litúrgica las que generan el villancico como creación poética colectiva en la que participan la poetisa, así como también los músicos, el coro de cantantes y la audiencia de fieles en la catedral. Además, las estrofas cantadas por el cantante que interpreta al negro hacen referencia de forma sistemática a varios platos (en particular, la cuajada, el garbanzo salado o tostón, el camote y el requesón) como ofertas a la Virgen para retardar su asunción y solicitar su favor o intercesión con Dios para que el esclavo obtenga su libertad. Esto es muy importante ya que, en virtud de ello, el arte culinario funciona 
como Sor Juana no sólo como causa eficiente de la creación poética sino como herramienta de liberación personal y social. ${ }^{6}$

Finalmente, el arte culinario opera en algunos casos como causa final de la creación poética en la medida en que funge como objetivo o fin del poema. Por ejemplo, en el poema 23 (p. 33) (que es un romance dedicado a la virreina María Luisa Manrique de Lara y fue escrito para acompañar un dulce de nueces hecho para prevenir un antojo de su destinataria que se hallaba embarazada), Sor Juana hace patente que el propósito del poema es no sólo corresponder a la generosidad de la virreina (que le había regalado una diadema adornada de plumas preciosas), sino la confección del dulce de nueces mismo. El dulce encarna una forma de sabiduría y de dote poética (en el sentido amplio del término) que Sor Juana espera que la virreina transmita al niño al consumir el dulce, puesto que el mismo Apolo (que es el dios del sol y la poesía) es visto como cocinera que sazona las nueces cuando maduran en el nogal:

Y, volviendo a mi Romance, les sazoné las cortezas

digo que él, allá en su lengua,

razonando medios días

y pronunciando centellas

me dijo: - "Esas nueces guarda dejé mis luces a ciegas:

de quien yo fui Cocinera;

que, al rescoldo de mis rayos

Que vivo con la experiencia,

Y estoy en edad de que sé

Donde el zapato me aprieta

Y habiendo visto el nogal,

y el dulce fruto que lleva,
Y mira que yo no soy

tan bobo como lo piensan

los que dicen que por Dafne

Que yo soy un Dios Doctor,

componen mi cabellera

conciba feto de luces,

concepto de rayos tenga;

que no es verdad el que el Cielo

${ }^{6}$ En este sentido, este poema de Sor Juana puede ser considerado como un antecedente de la idea que aparece en la novela de Laura Esquivel Como agua para chocolate (1989) en la que la protagonista Tita alcanza su liberación de las normas sociales opresivas que su madre, Mamá Elena, le impone a través de la práctica del arte culinario. 
No había de andarme tras

Laureles, a boca seca. siempre ingenerable sea.

Preséntaselas entonces;

Que si afable las acepta

Espero que por tu mano

Lograré mis conveniencias.

Estas estrofas del romance hacen patente que, para Sor Juana, el objetivo o fin del arte poético es la confección y el consumo del dulce de nueces. En la medida en que el dulce de nueces se considera como un receptáculo de la sabiduría y del don poético que Apolo quiere transmitir al hijo de la virreina, el arte culinario opera como causa final de la creación poética pues el papel de Sor Juana es meramente instrumental: sólo se limita (como ella misma admite) a guardar y a presentar las nueces, las cuales son el término o fin del proceso de creación que lleva a cabo Apolo. Así, pues, en vista de la evidencia presentada, podemos, entonces, concluir que el arte culinario funciona en la obra de Sor Juana como distintas causas de la creación poética, siguiendo los lineamientos de la teoría causal aristotélico-tomista.

\section{La relación entre lo bello y lo sabroso}

En algunos poemas ya trazados pudimos ver cómo Sor Juana utiliza lo comestible como sustituto o complemento de lo estético en sí. De cierta manera, esta manifestación poética parece común, ya que diversos autores disfrutan de la comparación entre lo bello y lo delicioso. En esta sección, demostraremos que la poetisa tiene compromisos aún más hondos, ya que la influencia platónica tanto como la aristotélico-tomista la hace más minuciosa en sus comparaciones electivas.

Por ejemplo, en el poema 56 (p. 76), como subraya Beuchot (1999, p. 28), y como comentamos en la sección previa, el amor que busca su Bien como término encuentra en el medio el dolor y el pesar que sufre al no conseguirlo:

Traigo conmigo un cuidado,

$\mathrm{Y} \tan$ esquivo, que creo

Que, aunque sé sentirlo tanto, 
Aun yo misma no lo siento.

[...] El término no es a quo,

que causa el pesar que veo:

que siendo el término el Bien,

todo el dolor es el medio.

Este amor es una apetencia, un deseo que tiene aspectos análogos al hambre (p. 77):

Tan precisa es la apetencia

Que a ser amados tenemos,

Que, aun sabiendo que no sirve,

Nunca dejarla sabemos.

[...] Así alimentando, triste,

La vida con el veneno,

La misma muerte que vivo,

Es la vida con que muero.

La misma analogía surge del Simposio de Platón. Para empezar, los participantes del Simposio llegan principalmente a comer y a beber, y se deciden a buscar la alabanza del dios del Amor. Así la gula en celebración gustativa y la admiración del Amor en forma oral se experimentan simultáneamente. Según el cuento de la sabia Diotima que relata Sócrates en este evento, el Amor es el hijo del dios de la riqueza y la diosa de la pobreza y es engendrado en el curso de un banquete. Por ello, el Amor es en esencia un espíritu que gobierna el deseo ya que nace precisamente bajo el signo del apetito. El deseo amoroso tiene como objeto propio el Bien, la forma abstracta e ideal de esa propiedad. El Bien, según la teoría Platónica, inhiere en los objetos materiales a través de la belleza, como la belleza de un amado, y una de las facetas del Bien es precisamente el buen sabor o sazón en los alimentos.

En Sor Juana, este Bien es el mismo Dios de la religión católica, quien es propiamente el objeto del amor de la poetisa, y, como destacamos en la cuarta sección, a su vez la causa final de este amor, 
según el esquema aristotélico-tomista. Sin embargo, el amor, aún siendo el amor a Dios, sigue siendo un anhelo que, como el hambre, causa dolor, pero que a su vez alimenta o nutre a quien lo sufre. De hecho, en la Loa para el auto sacramental de "El Divino Narciso", el Occidente cierra diciendo (p. 390):

¡Vamos, que ya mi agonía quiere ver como es el Dios que me han de dar en comida [...]!

Es importante subrayar que Sor Juana se distingue de Platón en cuanto a la manera que utiliza la imagen del Bien. Según la República de Platón, la poesía y los poetas no pertenecen a la sociedad ideal, ya que los poetas ofuscan el Bien, el cual es igual a la Verdad y a la Belleza. Por igual, se puede pensar que para el Platón del Fedón el deseo material sirve para anclar el ser humano al mundo, en vez de liberarlo como lo pudiera hacer la sabiduría: como el apetito es un deseo material, las artes culinarias pudieran considerarse innecesarias para la sociedad ideal. Sin embargo, para Sor Juana es claro que la poesía (en el sentido amplio del término) es indispensable, que la belleza y el buen sazón son centrales en mucha de su creación poética, y que a su vez las delicias culinarias sirven, como hemos visto, tanto de vehículo como de catalizador poético para distinguir y alcanzar el Bien. Esto se puede apreciar claramente en el poema 351 (p. 311) donde Sor Juana, al comentar el sacramento de la eucaristía, establece claramente un vínculo entre el apetito por el buen sabor y el amor del Bien:

Del alma sólo es Alimento

y así guía mi fervor

el Sustento del Amor

y no el amor del sustento.

Aquí crece la afición,

y es, en si la posesión la veo,

la posesión del deseo

deseo de posesión: 
pues tal deleite a dar viene

que, por más que la posea,

quien tiene lo que desea,

desea aquello que tiene.

Llegad, pues en su sabor

Todos los bienes se ven;

Que el amor del Sumo Bien

Es sumo bien del Amor.

El alma se alimenta con "el Sustento del Amor" de Dios, una nutrición espiritual análoga pero distinta a la nutrición o "sustento" corporal. En la última de las estrofas citadas Sor Juana completa esta metáfora al indicar que el "sabor" de este amor que es el "Sumo Bien" contiene "todos los bienes", albureando con su analogía homofónica entre el "Sumo Bien" y el "zumo" o jugo del Amor. Para Sor Juana, entonces, es claro que el deseo del Bien que es el Amor de Dios es una forma de hambre espiritual, y que el mismo Bien es un alimento espiritual que hasta sabor tiene.

Una intervención filosófica en este poema nos marca la independencia del pensamiento de Sor Juana con respecto al de Platón: según la visión en el Simposio, el deseo que es el Amor surge de una privación, que al solucionarse a través de posesión, tiende a acabar con el deseo. Sin embargo, nos aclara Sor Juana que el amor que le tenemos a Dios es un deseo que es excepcional, en cuanto a que "por más que" el amante "tiene lo que desea" sigue deseando "aquello que tiene". Es decir, este amor no es sujeto a las "reglas" del amor descrito por Platón, ya que no acaba al satisfacerse. A pesar de que la imagen del Sumo Bien es una imagen singularmente platónica, en Sor Juana se transforma en una imagen un tanto cristiana, en ser imagen del Amor de Dios, como plural, en incluir aspectos que Platón quizás no hubiera utilizado, como el sabor. Para Sor Juana, Dios origina todos los bienes materiales y espirituales, incluyéndose lo bello y lo sabroso, cuyas propiedades se unen en su eterno Amor.

\section{Conclusión}

Un grato regalo del volumen de escritura que tenemos de Sor Juana es que nos permite ver algo de la sistematicidad de su pensamiento a 
través de vínculos que forma repetidas veces a lo largo de su obra. En este ensayo exploramos la estrecha relación que ve la monja jerónima entre el verso y el alimento y, en particular, entre la creación poética y el arte culinario. Concluimos que en el pensamiento de Sor Juana ambas actividades comparten no solamente relaciones metafóricas, sino también metafísicas y estéticas.

Haciendo un análisis de su concepto de la creación y de la creatividad, que aborda con la reunión y transformación de ingredientes, pudimos ver que Sor Juana toma ideas herméticas cuando mezcla tanto metafóricamente como prácticamente el acto de componer poesía con el acto de preparar alimentos. Ambos parecen ser eventos mágicos, cuya promulgación se parece a la milagrosa creación del mundo. Dios mismo participa en ambos. A la vez, la poesía y la cocina pueden sustituirse la una por la otra, ya que sirven funciones similares, especialmente cuando se trata de la alabanza de lo divino.

La creatividad poética tiene un origen mítico en Sor Juana cuando ella lo equipara con un parto poco natural. En primer lugar, la habilidad poética proviene de un parto que se le hace posible a Sor Juana solamente al abandonar, en vez de ejemplificar, ciertos rasgos propiamente femeninos y tomar el velo de monja. En segundo lugar, esta destreza origina un estupor como el de una borrachera, la cual es producto de consumir los asientos de los versos de los grandes poetas. Según estos mitos, la creatividad poética de Sor Juana proviene tanto de lo innatural o monstruoso en ella como de un brebaje, una preparación que es poética-culinaria, pues los poetas magistrales, al componer poesía, son también vinateros capaces de embriagar y hasta "embarazar" al oyente y al consumidor.

En la cuarta sección sugerimos que el arte culinario funge como causa o catalizador de la creación poética de Sor Juana en una manera que puede describirse utilizando los cuatro conceptos aristotélicos de la causalidad. Es decir, el arte culinario sirve en Sor Juana, a veces, de causa final de su creación poética, pareciéndose como el fin de la actividad, hacia la cual se dirige; sirve a veces de causa material de su creación poética, proveyendo los "ingredientes" mismos de los versos como partes propias de la poesía; sirve a veces de causa formal de su creación poética, cuando la forma poética refleja la forma de un platillo; y sirve a veces de causa eficiente, cuando la gastronomía en sí sirve de motor que hace posible la creación poética. Así vemos que la creación poética y el arte culinario dependen el uno del otro.

Finalmente, argumentamos que para Sor Juana lo bello y lo sabroso comparten, de alguna manera, su origen formal, ya que ambos son 
aspectos del Sumo Bien. Las cosas bellas no solamente son análogas a las cosas sabrosas, sino que también las cosas más bellas pueden en sí tener sabor, aun en lo abstracto; mientras que las cosas más deliciosas tienden a ser bellas o a tener aspectos de belleza. Es decir, lo bello y lo sabroso no son bienes del todo separados. En la poesía de Sor Juana fungen como propiedades resonantes y hasta sustituibles la una por la otra.

En este ensayo no siempre hubo espacio para explorar todas las menciones de gastronomía y de poesía que entran en el análisis que ofrecemos, pero esperamos que se pueda comoquiera notar la vasta conexión entre estos dos aspectos centrales de la vida cotidiana de la monja, y que quizás al lector le interese seguir estudiando los textos que hicieron falta. Apreciamos, entonces, que la obra de esta celebrada escritora premie la detenida reflexión, incluso sobre temas que parecen accidentales durante una lectura superficial, y que hay muchos vínculos conceptuales que las investigaciones a futuro pueden destacar. Hay pie, en particular, para explorar las conexiones que existen en la obra de Sor Juana entre la perfumería y los olores y la creación poética. Quizás se pueden explorar otros aspectos táctiles, auditivos y visuales que se mezclen en su poesía, ya que Sor Juana luce una sensibilidad que parece sinestética. Finalmente, en su poema que sirve para acompañar el "recado de chocolate" a la Condesa de Galve, se empieza a ver una conexión entre el concepto de contabilidad y enumeración y el concepto de la métrica poética, y dado que la monja jerónima trabajaba de contadora, es más que probable que esta metáfora se pueda encontrar en otros de sus poemas. Su filosofía hermética podría descubrir una unidad entre la música y el número, y hasta tener una relación con una cosmovisión matemática. En fin, esperamos ver el continuo desarrollo de nuestro entendimiento de la magistral y políglota Sor Juana Inés de la Cruz.

\section{BIBLIOGRAFÍA}

Beuchot, Mauricio, 1999, Sor Juana, una filosofía barroca, Universidad Autónoma del Estado de México, Toluca.

Convento de San Jerónimo, 1979/1996, Libro de cocina: selección y transcripción atribuidos a Sor Juana Inés de la Cruz, Instituto Mexiquense de Cultura, Toluca.

de Valle-Arizpe, Artemio, 1932, Don Victoriano Salado Álvarez y la conversación en México : discurso leído en la sesión pública que el día 13 de noviembre de 1931 consagró a la memoria de tan ilustre escritor la Academia mexicana correspondiente de la española, Cvltvra, México. 
Esquivel, Laura, 1989, Como agua para chocolate, Planeta, México.

Hansen, David, 2018, "Sor Juana Inés de la Cruz and the Demands of Education", Educational Theory, vol. 68, no. 4-5, pp. 443-475.

Kirk, Stephanie, 2009, "El parto monstruoso: creación artística y reproducción biológica en la obra de Sor Juana Inés de la Cruz", Revista Iberoamericana, vol. 75, no. 227, pp. 417-433.

Lavín, Mónica y Ana Benítez, 2015, Sor Juana en la cocina, Debolsillo/Penguin Random, Ciudad de México.

Morino, Angelo, 2001, El libro de cocina de Sor Juana Inés de la Cruz, Grupo Editorial Norma, Bogotá.

Platón, 1871, El banquete, en Obras Completas, vol. 5, edición de Patricio de Azcárate, Medina y Navarro Editores, Madrid.

Ronsard, Pierre, 1866, Ouevres Complètes Vol. 6, A. Fracnk, París.

Sabat de Rivers, Georgina, 1976, El "sueño" de Sor Juana Inés de la Cruz: tradiciones literarias y originalidad, Tamesis Books Limited, Londres.

Sor Juana Inés de la Cruz, 2010, Obras Completas (decimosexta impresión), Porrúa, Ciudad de México.

Soriano Vallès, Alejandro, 2000, El Primero sueño de Sor Juana Inés de la Cruz. Bases tomistas, UNAM/Instituto de Investigaciones Estéticas, México.

Thomas, George A., 2015, The Politics and Poetics of Sor Juana Inés de la Cruz, Routledge, Nueva York.

Trabulse, Elías, 1982, El círculo roto: estudios históricos sobre la ciencia en México, Fondo de Cultura Económica, México.

Recibido el 27 de diciembre de 2019; revisado el 22 de mayo de 2020; aceptado el 25 de julio de 2020. 